\title{
Aortopulmonary Window and Double Aortic Arch. A Rare Association
}

\author{
Evander Moraes Botura, Marcelo Piazzalunga, Flavio Barutta Jr, Douglas S. Grion, Milton F. Neves Fo, \\ Ricardo Ueda
}

Londrina, PR - Brazil

\begin{abstract}
We report the case of a 27-year-old male patient with dyspnea on physical exertion. Clinical assessment and various tests led to the diagnosis of aortopulmonary window and double aortic arch. According to a literature search, this may be the first report on such association.
\end{abstract}

Aortopulmonary window, also know as aortopulmonary fenestration and aortopulmonary septal defect, is a rare anomaly ${ }^{1,2}$, accounting for $0.13 \%$ to $0.15 \%$ of the cases of congenital heart defect referred to a specialized center. Aortopulmonary window is an opening between the aorta and the pulmonary trunk. Two distinct separated semilunar valves must exist to establish the diagnosis of aortopulmonary window, and this defect should be differentiated from truncus arteriosus. The opening varies in size and is located adjacent to the semilunar valves or closer to the origin of the right pulmonary artery. The diagnosis is usually made early when major defects are present because of the significant left-to-right shunt ${ }^{1,2}$. Double aortic arch ${ }^{3-5}$ is usually an isolated anomaly; it may, however, occur in association with other defects, tetralogy of Fallot and transposition of the great arteries being the most common $^{6}$. Its origin is persistency of structures present in embryonic life, namely the $4^{\text {th }}$ branchial arch on both sides. When tracheoesophageal compression exists, the diagnosis is usually established during the first weeks of life ${ }^{4,5}$. The anomalies most commonly associated with aortopulmonary window are the following: aortic origin of the right pulmonary artery, interruption of the aortic arch ${ }^{1,2,6-8}$, tetralogy of Fallot, anomalous origin of the right coronary artery ${ }^{8}$, and the right aortic arch. No report exists in the literature about the association of aortopulmonary window and a double aortic arch.

\section{Case Report}

The patient is a 27 -year-old male who sought the car-

ULTRAMED-MEDTAC Imagem em Medicina

Mailing address: Marcelo Piazzalunga - Rua Santos, 646/102 - 86020-020 Londrina, PR - Brazil - E-mail: marcelop@cardiol.br

English version by Stela Maris C. e Gandour diology outpatient care clinics in August 1999 complaining of dyspnea on strenuous and moderate exertion. He reported no significant clinical or surgical antecedent in his previous history.

On physical examination, the patient was in good condition, anicteric, cyanotic, with healthy coloring, and clubbing of his fingers.

His blood pressure was $120 / 90 \mathrm{mmHg}$, his heart rate was $75 \mathrm{bpm}$, the cardiac rhythm was regular, and the $2^{\text {nd }}$ cardiac sound was loud on the $2^{\text {nd }}$ left intercostal space. The abdomen was normal, and the rest of the physical examination did not reveal any abnormalities.

The electrocardiogram revealed sinus rhythm and significant hypertrophy of the right chambers (fig. 1). The chest X-ray in the pulmonary artery revealed an increase in the caliber of the hilar arterial vessels more evident to the left, and bulging of the middle arch. The echocardiogram showed hypertrophy of the right ventricle with systolic dilation and dysfunction, and tricuspid insufficiency with right ventricular systolic pressure estimated as $100 \mathrm{~mm} \mathrm{Hg}$ (significant pulmonary hypertension).

Pulmonary hypertension of unknown origin was the clinical diagnosis established.

The hemodynamic study revealed severe pulmonary hypertension $(110 \mathrm{mmHg})$, aortopulmonary window, double aortic arch (fig. 2), and normal coronary arteries.

Nuclear magnetic resonance showed a wide aortopulmonary window ( $40 \mathrm{~mm}$ in its major diameter), significant dilation of the ascending aorta and of the central pulmonary arteries, and complete double aortic arch (fig. 3). Significant tracheoesophageal compression was observed at the level of the double aortic arch.

Contrast radiography of the esophagus confirmed the extrinsic compression.

\section{Discussion}

Some characteristic findings in this patient are particularly noteworthy. In addition to the rarity of the incidence of these 2 diseases occurring alone, this may be the first report 


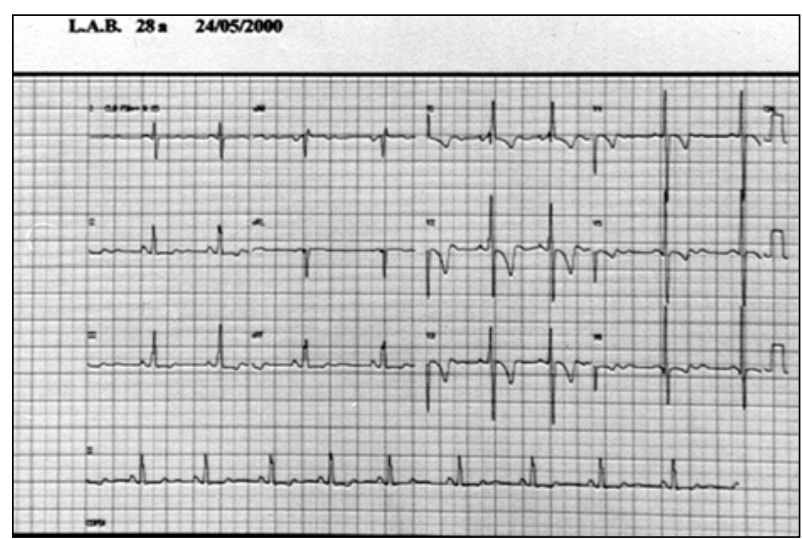

Fig. 1 - Electrocardiogram showing sinus rhythm and significant hypertrophy of the right chambers.

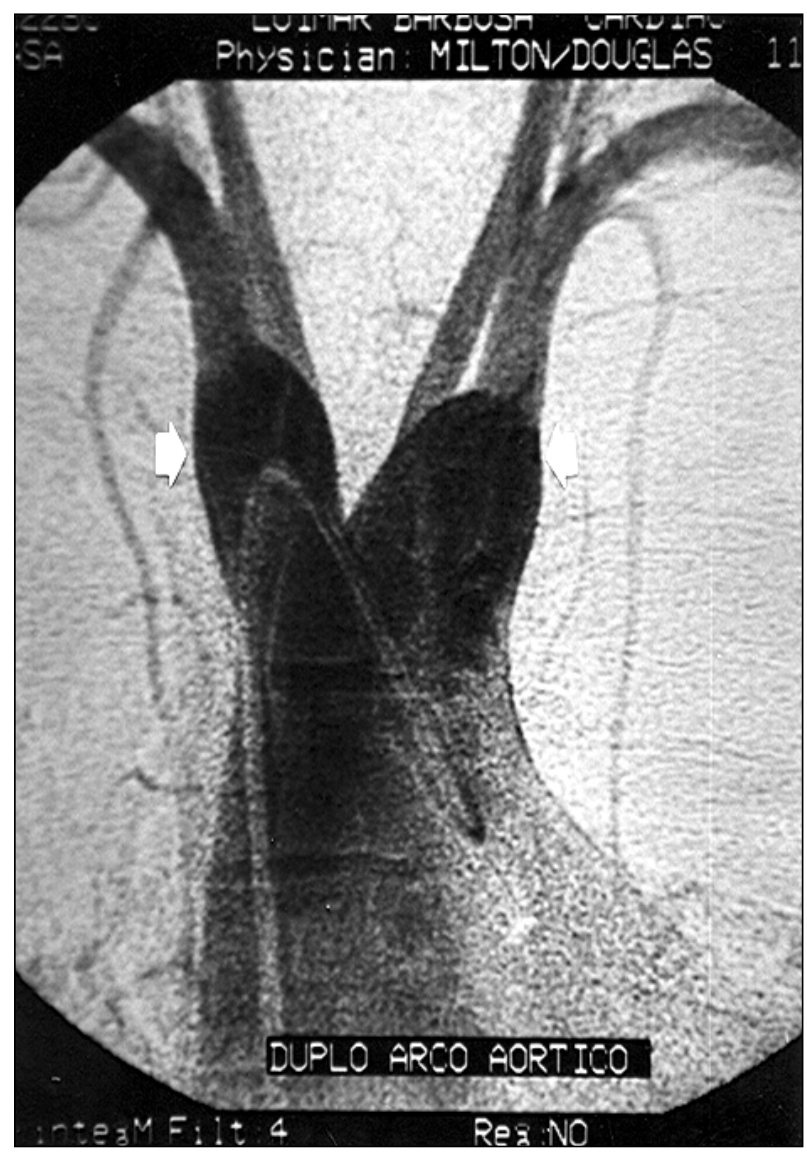

Fig. 2 - Hemodynamic study showing double aortic arch (arrows).

ever made of their association. Furthermore, the late appearance of significant symptoms in this patient is also important.

An aortopulmonary window ${ }^{1,2}$ is usually wide, causing important symptoms in the first weeks or months of life, which result from the significant left-to-right shunt, and these symptoms are similar to those observed in the presence of large ventricular septal defect or a wide arterial canal. Our patient had cyanosis, dyspnea on moderate exertion, due to existing pulmonary hypertension, in addition to clubbing of his fingers, which is a characteristic finding of

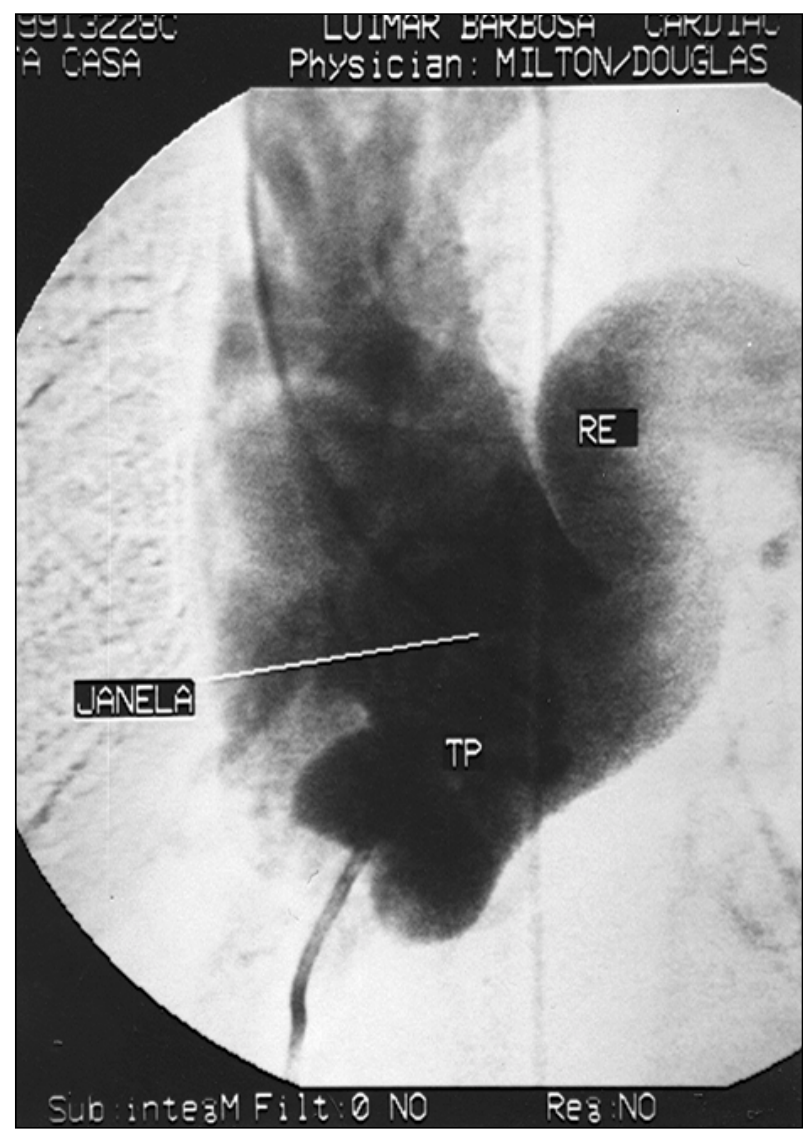

Fig. 3-Axial section of nuclear magnetic resonance showing wide aortopulmonary window (arrow). Ao- aorta; AP- pulmonary artery.

central cyanosis (usually secondary to cyanotic congenital heart defect or pulmonary disease with hypoxia). If no surgical correction occurs, pulmonary vascular disease develops early in the first year of life.

Diagnosis of this anomaly and distinguishing it from arterial canal and persistent truncus arteriosus are made with two-dimensional echocardiography ${ }^{8}$, but the definitive identification of aortopulmonary window and associated malformations may require hemodynamic study and selective angiocardiography. Anomalous origin of the coronary arteries may occur in approximately $5 \%$ to $10 \%$ of the patients with aortopulmonary window, is difficult to diagnosis preoperatively (because the high perfusion pressure resulting from the aortopulmonary communication favors good coronary flow), and is an example of the importance of the hemodynamic study in this type of patient ${ }^{8}$. Even though some patients may survive until adulthood with aortopulmonary window, most of them die early, until the $2^{\text {nd }}$ decade of life, unless surgical correction is performed. Elective surgery is indicated in all symptomatic infants between the $3^{\text {rd }}$ and $6^{\text {th }}$ months of life.

The term "vascular ring" ${ }^{3-5}$ is used for those malformations of the aortic arch or of the pulmonary artery that show an abnormal relation with the trachea and the esophagus, and they represent less than $1 \%$ of congenital cardiovascular defects. 
The most common and severe "vascular ring" is the one produced by a double aortic arch in which the $4^{\text {th }}$ embryonic left and right aortic arches persist. In the most common type of double aortic arch, a left arterial ligament or duct exists, and both arches are patent, the right being larger than the left.

The symptoms ${ }^{4}$ produced by vascular rings result from the anatomical constriction of the trachea and esophagus. They usually appear early in the complete double aortic arch, and consist mainly of respiratory difficulty, cyanosis (especially associated with feeding), stridor, and dysphagia.

The electrocardiogram is normal unless associated cardiovascular anomalies exist. Contrast radiography of the esophagus is a useful screening procedure and usually shows a prominent posterior indentation at the level of the "vascular rings". Selective angiography delineates the anatomy of the aorta and its branches, and the course of the major pulmonary arteries. Computerized axial tomography and nuclear magnetic resonance ${ }^{9,10}$, however, show the spatial relation between the "vascular ring" and the trachea and esophagus more clearly, allowing better surgical programming.
The severity of the symptoms and anatomy of the malformation are the major factors for establishing the appropriate treatment.

In the present case, in addition to the lack of a report in the medical literature about the association of these diseases, this being probably the first case ever reported, the long symptom-free survival of our patient is notable in the presence of a wide aortopulmonary window and complete double aortic arch with significant tracheoesophageal compression, which are anomalies that usually cause important and early symptoms.

The difficulty in making a diagnosis with the initial echocardiography was mainly due to the presence of severe pulmonary hypertension with equalization of systemic and pulmonary pressures, and consequent low flow through the defect.

Selective angiocardiography and nuclear magnetic resonance were extremely useful for diagnosing and analyzing the anatomical relations, allowing identification of the defects and their consequences.

\section{References}

1. Brooks MM, Heymann MA. Aortopulmonary window. In: Emmanouilides GC, Riemenschneider TA, Allen HD, et al, (eds): Moss and Adams' Heart Disease in Infants, Children, and Adolescents, Including the Fetus and Young Adult $\left(5^{\text {th }}\right.$ ed.). Baltimore: Willians \& Wilkins, 1994: 764-8.

2. Fyler DC. Aortopulmonary window. In: Fyler DC, (ed): Nadas' Pedriatic Cardiology. Philadelphia: Hanley \& Belfus, 1992: 693-5.

3. Weinberg PM. Aortic arch anomalies. In: Emmanouilides GC, Riemenschneider TA, Allen HD, et al (eds): Moss and Adams' Heart Disease in Infants, Children, and Adolescents, Including the Fetus and Young Adult ( $5^{\text {th }}$ ed). Baltimore: Willians \& Wilkins, 1994: 810-37.

4. Kocis KC, Midgley FM, Ruckman RN. Aortic arch complex anomalies: 20-year experience with symptoms, diagnosis, associated cardiac defects, and surgical repair. Pediatr Cardiol 1997; 18: 127-32.

5. Valletta EA, Pregarz M, Bergamo-Andreis IA, Boner AL. Tracheoesophageal compression due to congenital vascular anomalies (vascular rings). Pediatr Pulmonol 1997; 24: 93-105.

6. Gloss G, DelgadoLeal F, Vazquez G, Calderon-Colmenero J, Buendia A. The aortopulmonary window. A reporter of 4 cases. Arch Inst Cardiol Mex 1994; 63: 149-52.

7. Terrapon M, Schneider P, Friedli B, Cox JN. Aortic arch interruption type a with aortopulmonary fenestration in an offspring of a chronic alcoholic mother ("fetal alcohol syndrome"). Helvet Paediatr Acta 1997; 32: 141-8.

8. Soares AM, Atik E, Cortez TM, et al. Janela aortopulmonar. Análise clínico-cirúrgica de 18 casos. Arq Bras Cardiol 1999; 73: 59-66.

9. Weinberg PM, Hubbard AM, Fogel MA. Aortic arch and pulmonary artery anomalies in children. Semin Roentgenol 1998; 3: 262-80.

10. Lee ML, Wang JK, Wu MH, Lue HC, Chiu IS, Chang CI. Clinical implications of isolated double aortic arch and its complex with intracardiac anomalies. Int J Cardiol 1998; 63: 205-210. 